\title{
MedChemComm
}

\section{Expression of concern: Identifying the inhibitory mechanism of apigenin on the insulin ligand-receptor binding}

Cite this: Med. Chem. Commun., $2015,6,2232$

DOI: $10.1039 / \mathrm{c} 5 \mathrm{md} 90056 \mathrm{e}$

www.rsc.org/medchemcomm

\author{
Richard Kelly
}

Expression of concern for 'Identifying the inhibitory mechanism of apigenin on the insulin ligand-receptor binding' by Yong Yang, Med. Chem. Commun., 2015, 6, 1190-1195.

The following article 'Identifying the inhibitory mechanism of apigenin on the insulin ligand-receptor binding' by Yong Yang has been published in MedChemComm. The article reports that using single-molecule force measurement and fluorescence imaging it is demonstrated that apigenin inhibits insulin-induced dimerization of the insulin receptor (IR) through blocking ligand-receptor interactions. This inhibitory effect is also confirmed by flow cytometry and molecular docking. Furthermore it is shown that apigenin impairs cancer cell proliferation. The role of apigenin in suppressing tumor growth was also evident in an in vivo model, indicating a potential future application of apigenin in cancer therapy.

The Royal Society of Chemistry has been contacted by the author of this article to inform us of a problem with the authorship and some portions of text overlap, which the author attributes to an editing company.

Upon close examination the Executive Editor has found extensive text overlap with a previously published paper by Yong Yang and a co-author (Quercetin suppresses insulin receptor signaling through inhibition of the insulin ligand-receptor binding and therefore impairs cancer cell proliferation, Feng Wang and Yong Yang, Biochemical and Biophysical Research Communications, 2014, 452, 1028-1033). Further to this the Executive Editor has significant concerns over the validity of the reported findings.

MedChemComm is publishing this expression of concern in order to alert readers to these concerns as the on-going investigation is expected to take a significant amount of time to complete. The Royal Society of Chemistry is currently seeking support from the affiliated institution in order to investigate the matter and establish whether the reported results are sound.

This notice will be updated when a final outcome is reached.

Richard Kelly

11th November 2015

Executive Editor, MedChemComm 